Fostering an Inclusively Relevant Mathematics Environment:

The Case for Combining Social-Justice and Utility-Value Approaches

\author{
Stacy J. Priniski ${ }^{1}$ and Dustin B. Thoman ${ }^{2}$ \\ ${ }^{1}$ Michigan State University \\ ${ }^{2}$ San Diego State University
}

\begin{abstract}
Author Note
This manuscript is based upon work supported by the Mindset Scholars Network's Inclusive Mathematics Environments Early Career Fellowship, with funding provided by a grant from the Bill \& Melinda Gates Foundation. The content is solely the responsibility of the authors and does not necessarily represent the views of the Mindset Scholars Network or the Bill \& Melinda Gates Foundation.

Correspondence concerning this working paper should be addressed to Stacy Priniski, Michigan State University, East Lansing, MI. prinisk3@msu.edu.
\end{abstract}




\begin{abstract}
Despite a common belief that mathematics is neutral and apolitical, a critical analysis reveals a legacy of mathematics education that has catered to the dominant (white, middle-class) culture, and served to stratify students along the lines of race, gender, socioeconomic status, and other dimensions of identity and difference. However, there is increasing awareness that mathematics education should be reformed to make it more relevant to all students' lived experiences. In this paper we make the case for why the goal of increasing the relevance of math is closely related to (and can be achieved in service of) inclusion and equity. We discuss two very different approaches to promoting relevance in the classroom and suggest a way forward to combine those two approaches in pursuit of equity and inclusion. Specifically, we review two bodies of literature: utility-value interventions, which stem from the motivation literature and focus on personal relevance, and teaching and learning math for social justice, which stems from the critical mathematics education literature and focuses on cultural relevance. Our review suggests that these two literatures, which have been disparate in terms of their epistemological traditions, theoretical foundations, and methodological approaches, could be complementary and even synergistic in promoting inclusive math learning environments for all students.
\end{abstract}

Keywords: relevance, utility-value interventions, teaching and learning math for social justice, critical mathematics, inclusion, middle grades, mathematics education 


\section{Fostering an Inclusively Relevant Mathematics Environment: \\ The Case for Combining Social-Justice and Utility-Value Approaches}

Math is one of the few subjects presented with little to no historical or cultural context. A prevailing view is that math is "neutral" and therefore intended to be taught at an abstract level, far removed from social or cultural matters (e.g., Anderson, 1997). These beliefs about the neutrality of math set teachers with the impossible task of convincing their students that math is simultaneously far removed from the forces that shape their lives but also so important for their lives that they need to spend much of them memorizing its rules and procedures. It's a problem that has challenged math teachers who wish to instill in their students a love of learning and of mathematics in particular, but it goes beyond a struggle to help students see the relevance of learning math. This subject that has been stripped of context has also been propped up as a gatekeeper to higher education and careers, with serious economic and social consequences for students whose math test performance labels them as low-achieving (e.g., Oakes, 2005; Stinson, 2004; U. S. Department of Education, 1997). And the gatekeeper is far from neutral. There is a pervasive societal belief that some students are capable of learning math whereas others are just not "math people" (e.g., NCTM, 2000), and the status quo of mathematics education in the United States is leaving minoritized communities behind.

In light of these issues, there is increasing awareness that mathematics education needs reform to make instruction more relevant to students and outcomes more equitable. Recent changes to educational standards reflect this. For example, the Common Core State Standards for School Mathematics define proficiency in math as including the practice of mathematical modeling: students at all grade levels should be able to "apply the mathematics they know to solve problems arising in everyday life, society, and the workplace" (National Governors Association Center for Best Practices \& Council of Chief State School Officers, 2010, p. 7). Likewise, National Council of Teachers of Mathematics' (NCTM) Principles and Standards for 
School Mathematics recommends engaging students in applying math to address societal problems: "students should be able to use their knowledge to understand societal issues . . [and] school experiences should include opportunities to learn mathematics by working on problems arising in contexts outside of mathematics" (NCTM, 2000, pp. 65-66). In the case of NCTM, equity is also a priority. The very first of NCTM's six principles for school mathematics is equity. In this paper we will make the case for why the goal of increasing the relevance of math is closely related to (and can be achieved in service of) the goal of increasing equity. We describe two very different approaches to promoting relevance in the classroom stemming from distinct research traditions, and suggest a way forward to combine those two approaches in pursuit of equity and inclusion.

\section{The Role of Relevance in Inclusivity}

The term "relevance" can mean slightly different things in different disciplines, but broadly speaking, relevance refers to "a personally meaningful connection to the individual" (Priniski et al., 2018, p.12). These connections range from relatively surface-level connections (e.g., to a memory: "that reminds me of..."), to perceived utility/usefulness (e.g., "I can use this in my everyday life"), to deep identification with the topic (e.g., "I'm a math person"). We focus here on two types of relevance: personal relevance and cultural relevance. Although personal and culture relevance are intertwined, research on personal and cultural relevance tend to focus on separate parts of the relevance continuum. Personal relevance work is largely focused on utility and cultural relevance work is largely focused on identification (i.e., connections between the topic and one's cultural identity). Work on personal relevance is primarily situated within the motivation literature in educational psychology and focuses on the individual's perceptions of and relationship with a topic. Studies of personal relevance have typically focused on the impact of making specific activities or instructional materials more personally relevant to students by emphasizing their utility, as a means fostering individual motivation, interest development, and performance (see Priniski et al., 2018, for a review). 
Work on cultural relevance is focused primarily on the relevance of the classroom environment to groups of students, specifically students from marginalized or minoritized communities. This work is exemplified by the family of approaches known as culturally relevant education (CRE; e.g., Gay, 2000; Ladson-Billings, 1995) ${ }^{1}$ which involve the use of teaching practices and pedagogy to foster connections between mathematics and students' lived experiences and funds of knowledge (i.e., the various ways of knowing and expressing knowledge of mathematics, which may differ by culture and background; González et al., 2005). The goals of CRE include development of cultural competency (i.e., "helping students to recognize and honor their own cultural beliefs and practices while acquiring access to the wider culture, where they are likely to have a chance of improving their socioeconomic status and making informed decisions about the lives they wish to lead;" Ladson-Billings, 2006, p. 36) and sociopolitical consciousness (i.e., the ability to "recognize, understand, and critique current and social inequalities;" Ladson-Billings, 1995, p. 476).

Simic-Muller, Fernandes, and Felton-Koestler (2015) outline three different reasons for connecting mathematics to real-world contexts: (a) preparation for future careers and everyday lives, (b) illustrating how all students' backgrounds and knowledge are valued in the classroom by connecting to students' home lives, communities, and cultural backgrounds, and (c) preparation of active and engaged citizens. These reasons correspond roughly to the typical ways in which personal (a) and cultural (b and c) relevance have been applied to mathematics classrooms, but we would argue that all three are necessary to overcome a legacy of mathematics education that has catered to the dominant (white, middle-class) culture (e.g., Irvine, 1990; Moses \& Cobb, 2001; Stinson, 2004; Tate, 1995).

\footnotetext{
${ }^{1}$ Consistent with Aronson and Laughter (2016) and Dover (2013), we use culturally relevant education to refer broadly to the family of research exemplified by Gay's work on culturally responsive teaching (e.g., Gay, 2000), which focuses on teacher practices that can foster cultural relevance, and Ladson-Billings' work on culturally relevant pedagogy (e.g., Ladson-Billings, 1995), which focuses on ways the teacher's overall approach and paradigm for mathematics education can foster cultural relevance.
} 
Although mathematics is often described as neutral and apolitical, scholars have argued that a critical analysis reveals quite the opposite. Decisions about what is taught are political; who decides what is taught is political; the assertion that mathematics is neutral is itself a political stance, and above all, the way in which mathematics is used to stratify and track students is political. Mathematics is one of the few subject areas taught with "little or no historical, cultural, or political references... [which] reinforces the institutionalization of Eurocentrism, class elitism, and sexism" (Anderson 1997, p 296). Indeed, many of the mathematical principles and procedures that are named after European mathematicians were actually discovered first by other cultures (e.g., Pascal's triangle was discovered centuries earlier by the Chinese), but without this historical context status quo mathematics sends the message that if other cultures had mathematics it must have been primitive, replaced by contemporary European approaches (Lesser \& Blake, 2007).

Even attempts to make mathematics more relevant can be problematic when textbooks have word problems crafted to be relevant for the "average" (white, middle-class) student. Analysis of these examples reveals problematic content, including gender stereotypes and reinforcement of the social hierarchy (Lesser \& Blake, 2007). For example, Trexler (2013) noted that a "standard" story problem about whether it was more cost efficient to buy daily or weekly bus passes led to systematic differences based on parental occupation: students whose parents had white-collar jobs (working Monday-Friday) answered the question differently than those whose parents worked multiple jobs and/or worked more than five days a week. In other words, even the attempts to make math more relevant can backfire if they do not take into account the diversity of student experiences, frames of reference, and cultural values.

Most importantly, we can see that status quo mathematics education is not inclusive because there are persistent differences in test scores and advanced math placements along the lines of race, ethnicity, gender, and socioeconomic status (e.g., Bond \& Chernoff, 2015; Martin et al., 2010; Stinson, 2004). The impact of this exclusion is grave, because mathematics 
is a gatekeeper to higher education, economic opportunity, and full practice of citizenship (e.g., Frankenstein, 1995; Moses \& Cobb, 2001; Tate, 1995 Skovsmose, 1994;). As Gutstein (2007) argued, "To deny [students from minoritized communities] opportunities to develop the knowledge and dispositions with which to analyze, critique, and change the conditions of their

lives and of society as a whole is to maintain, reproduce, and extend injustice and inequality" (p. 440). Thus, students from minoritized communities are structurally excluded from mathematics opportunity, are unlikely to see themselves or their communities reflected in the whitewashed curriculum, and are even unlikely to find contextualized "relevant" math story problems to resonate with their lived experiences.

In sum, we believe that status quo mathematics education is exclusionary in part because mathematics is not made personally or culturally relevant for students, with more negative consequences for students from marginalized and minoritized communities. In order for a math classroom to be inclusively relevant, it needs to be for all students in the sense that (a) it is not against them (i.e., not exclusionary, not perpetuating stereotypes about math ability), (b) it is designed with them in mind (i.e., instruction resonates with their lived experiences, cultural values, and background), and (c) it invites them to co-create math instruction that is meaningful for them (bringing each individual student into the process). In discussing strategies for promoting inclusivity through relevance, we review two sets of literature: utility-value interventions, which stem from the motivation literature and focus on personal relevance, and teaching and learning math for social justice, which stems from the literature on critical mathematics education and focuses on cultural relevance.

\section{Positioning the Research Synthesis}

As social psychologists who do primarily quantitative work related to personal relevance, we come to this work motivated by three questions: (a) How can researchers like us learn from the great work of researchers who focus on cultural relevance, particularly from a critical race perspective, in service of promoting equity and inclusion? (b) What insights from work on 
personal relevance can be used to inform work on cultural relevance, in service of promoting equity and inclusion? (c) What would it look like to take a holistic approach to creating an inclusive math environment incorporating insights from both bodies of work? Motivated by these questions, we sought potential areas of commonality and synergy across literatures that do not often speak to each other. We chose to focus on utility-value interventions and teaching and learning math for social justice (TLMSJ) because they are radically complementary: we see clear commonalities between them, but we also recognize many important differences. They focus on different aspects of relevance (personal vs. cultural); they are rooted in different epistemological traditions; the evidence base is different (primarily quantitative vs. qualitative), etc. We acknowledge that these differences are non-trivial and that some may see utility-value and TLMSJ approaches to be incompatible or even irreconcilable, but we engage in this synthesis believing that both approaches have merit, that both are imperfect, and that both offer valuable insights that are needed for a holistic approach to creating inclusively relevant mathematics environments.

Therefore, in this research synthesis, we conducted a conceptual review (Kennedy, 2007) of the literatures on utility-value interventions and TLMSJ. Article searches were conducted in EBSCOhost, ERIC, and Psychlnfo databases. We began with the search terms "math" + "social justice" + "middle school" for the TLMSJ literature and "utility value" + "math*" + "middle school" for the utility-value interventions literature. We then extended our search for utility-value articles to include other STEM and high school contexts. Finally, we examined the references of each article we found and searched Google Scholar to identify additional sources that would help us to address the three questions listed above. For both TLMSJ and utility-value interventions, we review the theoretical foundations of the approach and the evidence base that contributes insights for ways to create inclusively relevant mathematics environments. Finally, we offer our thoughts on the commonalities and synergies between these two approaches and directions for future research to leverage the strengths of both approaches. 


\section{Utility-Value Interventions}

Utility-value interventions are grounded in Eccles and colleagues' expectancy-value theory (e.g., Eccles et al., 1983; Eccles \& Wigfield, 2000). According to this theory, a student's motivation is most proximally determined by their answers to two questions: "Can I do this?" (expectation of success on the task) and "Do I want to do this?" (value of the task). These ability and value beliefs are, in turn, determined by a complex network of psychological, social, cultural, and environmental factors, including the student's characteristics and past experiences, socializers' (e.g., parents' and teachers') attitudes and behaviors, cultural stereotypes relevant to the subject matter or the student's identity, and characteristics of the task at hand. Students' value beliefs can be further divided into four major components: intrinsic/interest value (the student's inherent enjoyment of the task), utility value (the usefulness of the task for achieving the student's goals), attainment value (the importance of the task for the student's sense of identity), and cost value (the negative aspects of engaging in a task, such as limitations on the student's time, energy, and effort). The utility-value intervention focuses in on the utility facet of value beliefs, seeking to help students make connections between their schoolwork and things that are important to them.

Utility-value interventions are based on a foundation of correlational studies in a variety of education contexts that have shown relations between perceived utility value and positive academic outcomes, such as increased interest, effort, and performance (e.g., Brophy, 1999; Harackiewicz et al., 2008; Hulleman et al., 2008; Wigfield, 1994) and laboratory studies primarily focused on math learning that have shown experimental manipulations of utility value can improve outcomes such as interest, persistence, academic self-regulation, and effort (e.g., Canning \& Harackiewicz, 2015; Durik et al., 2015; Hulleman et al., 2010). Utility-value interventions make use of a range of strategies to promote perceived utility value in the classroom, but the most common is to have students write about how what they're learning is relevant and/or useful to them in their own lives (or to close friends or family members). For 
example, in a landmark study by Hulleman and Harackiewicz (2009), $9^{\text {th }}$ grade science students were asked to select a topic they were currently learning in class and write a one-paragraph essay applying that topic to their life or the life of someone they knew (intervention condition) or write a one-paragraph summery of their topic (control condition). They did this repeatedly over the course of the semester, as part of their review activities (for credit) before each test. The intervention resulted in higher grades in the science course and higher interest in science at the end of the semester (compared to the control condition) among students with low expectations of success in the course. The effects for these students were large, with grades increasing about $2 / 3$ of a grade point and interest increasing 0.36 points on a $1-5$ scale (approximately $1 / 3$ of a standard deviation).

A growing body of literature has shown that utility-value interventions are effective in four-year college contexts, where the intervention has most often been implemented as a series of 1-2 page writing assignments (although the evidence in two-year college contexts is mixed; Canning et al., 2019; Kosovich et al., 2019). Randomized controlled trials have shown positive effects on interest, perceived utility value, persistence in science majors, and (most consistently) performance (see Harackiewicz \& Priniski, 2018; Lazowski \& Hulleman, 2016; Rosenzweig \& Wigfield, 2016, for reviews). Although the early utility-value intervention studies were conducted primarily in college contexts and were not initially used as a tool for promoting inclusivity (cf. Shechter et al., 2011), there is reason to believe that these interventions could be particularly impactful for middle school students generally, and for students from minoritized communities in particular.

\section{Utility-Value Interventions in Middle School}

Changes in motivation over time are complex and variable. However, many studies have shown that students' motivation (and especially their expectations for success) declines during the middle school years, a pattern that is more pronounced in math and science (for reviews see Dweck \& Elliott, 1983; Wigfield et al., 2015). Middle school is also an important period for 
identity development: students are beginning to define themselves with respect to STEM (e.g., "I am [not] a math person;" Dweck \& Master, 2009; Eccles, 2009), and their STEM motivation is becoming predictive of their career pursuits (Hall et al., 2011). At the same time, students are beginning to choose STEM electives and enter "tracked" courses, setting their trajectory in a way that can impact the availability of choices for advanced STEM education in high school and college (e.g., Maltese \& Tai, 2011; National Science Foundation, 2012; Wang \& Eccles, 2013). Thus, middle school is an important period to mitigate potential declines in motivation and foster math identity development, and helping students to see math as personally relevant is one important tool for accomplishing those goals.

Whereas utility-value interventions in college classrooms have almost exclusively involved writing assignments, the implementations of the intervention are more varied in middle and high school contexts. Researchers and educators have adapted the intervention to suit the needs of middle-grades teachers and students in several ways, including reducing the writing burden on students (compared to the 1-2 page essays typical in college contexts), focusing on utility for different types of goals (e.g., career goals, social goals), and combining "directlycommunicated" utility value (teachers providing information about utility) with "self-generated" utility value (students making connections for themselves, as in the writing tasks described above; Canning \& Harackiewicz, 2015). Because the literature on utility-value interventions in middle-school math contexts is small, we combine it here with students in other STEM and high school contexts. As with the early work in college contexts, these studies were conducted with relatively non-diverse samples and had no emphasis on inclusivity; we return to the question of utility-value interventions for inclusivity in the next section.

As noted above, a landmark utility-value intervention study in $9^{\text {th }}$ grade science classes demonstrated that asking students to write short paragraphs about the relevance of course topics to their own lives or the lives of people they knew resulted in increased interest and performance for students with low expectations for success (Hulleman \& Harackiewicz, 2009). 
Akcaoglu and colleagues (2018) tested the same type of writing activity with a randomized controlled trial in $5^{\text {th }}$ and $6^{\text {th }}$ grade science courses, also in the Midwestern United States. Although students in this study completed the writing activity only once (whereas students in the Hulleman \& Harackiewicz study completed multiple writing activities throughout the semester), Akcaoglu and colleagues (2018) found that the intervention was associated with increases in perceived utility value for all students, on average, one month after the intervention $(d=.29)$, demonstrating that middle-school students were capable of self-generating utility-value connections in writing and benefitted from doing so.

Gaspard and colleagues (2015) tested a different intervention format in $9^{\text {th }}$ grade math courses in Germany. The intervention involved a 90-minute psychoeducational presentation by researchers about math confidence and the relevance of math, followed by one of two types of utility-value writing activities. In one condition, students wrote essays (similar to the previous studies); in the other condition, students read quotations from young adults about the usefulness of math and then evaluated (in writing) which quotes were the most relevant to them personally. In both cases, similar writing tasks were completed three times. Classrooms randomly assigned to a wait-list control group did not receive the intervention presentation until after the study was over, and their homework diary tasks were unrelated to utility value. Gaspard and colleagues (2015) examined students' value beliefs before the intervention (pretest survey), on a 6-week post-test survey and 5-month follow-up survey. They found that compared to the waitlist control group, students in both utility-value conditions reported higher perceived utility value of math on the post-test and follow-up surveys. The effect on perceived utility value was somewhat stronger for the quotes condition $(d s=.38-.48)$ than the essay condition $(d s=.16-.18)$, and the quotes condition also increased attainment value of math $(d s=$ $.25-.26$ ) and interest in math (follow-up only, $d=.19$ ). Additional studies from the same project found that the quotes condition also increased students' expectancies, effort, and math achievement (Brisson et al., 2017) and that effects of these interventions were stronger for 
students whose parents had lower interest and utility value for math (Häfner et al., 2017). Rosenzweig and colleagues (2019) also compared essay and quote versions of the intervention in a one-time activity in online high school math courses in the Southeastern United States. They found that only the quotes condition significantly increased perceived utility value immediately after the intervention $(d=.32)$.

Hulleman and his colleagues are also working on making the utility-value intervention easier for teachers to implement (Motivate Lab, 2018). They established a collaboration with middle- and high-school math and science teachers to enact a design and prototyping process that would make the intervention tasks more accessible to teachers and students. The new version of the intervention materials included worksheets that would guide students through a process of thinking about their life (people, hobbies, goals that are important to them), think about the topics they're currently studying, make connections between those topics and their lives, and choose one connection on which to elaborate. In addition, the collaboration developed a "playbook" and resources for teachers who want to use the activity in their courses, and a "prep activity" very similar to the quotes condition from previous studies (Gaspard et al., 2015; Rosenzweig et al., 2019). Initial testing of this new system in middle and high schools in the Eastern United States indicated that more students believed math and science were relevant to their lives after the intervention (increased from 56\% to 64\%; Motivate Lab, 2018).

Together, these initial attempts to adapt the utility-value intervention for secondary school contexts indicate that these interventions can be effective in helping students to find personal relevance in STEM course topics. However, these studies were conducted with primarily white samples, leaving unanswered questions of the viability of utility-value interventions as tools for inclusive teaching. Notably, other relevance studies conducted in more diverse contexts revealed very similar effects, although they were not specifically based in expectancy-value theory or utility-value intervention work. Duffin and colleagues (2016) found that an inquiry-based project designed to help high-school students connect chemistry concepts 
to consumer products and careers. The intervention increased chemistry knowledge, relevance for chemistry, and intent to take more chemistry in the future in a sample of primarily students of color. Woolley et al. (2013) found that a whole-school curriculum involving lessons about how the material in all major subjects relates to careers (CareerStart) increased math (but not reading) achievement over the course of middle school in a sample that was primary students of color. These studies highlight the generalizable benefits of fostering relevance in the classroom (cf. Herrera, 2019). Furthermore, recent work in both middle and high school contexts suggests that the utility-value intervention specifically can also be adapted to better suit diverse, multicultural classrooms.

\section{Utility-Value Interventions for Inclusivity}

Utility-value interventions have been part of a surge of work over the last two decades on relatively brief, low-cost social-psychological interventions that can have big effects (Walton, 2014; Wilson, 2006; Yeager \& Walton, 2011). Due to a confluence of factors, research in this area is in transition, from being designed to help all students or underachieving students (especially those with low performance expectations or a history of low performance) to being designed to address achievement disparities along lines of demographic difference. In the social psychological literature, there are calls for social-psychological interventions to be culturally grounded (e.g., Brady et al., 2017), and initial attempts have been successful. For example, the values-affirmation intervention has been adapted for Latinx students (Covarrubias et al., 2016) and first-generation college students (Tibbetts et al., 2016, 2018). Furthermore, in the literature on motivation and persistence in STEM, there is increasing awareness that students from minoritized communities have different reasons for pursuing STEM than their peers; namely, these students are more likely, due in part to their cultural background, to endorse prosocial goals (e.g., wanting to pursue medicine to improve health in their own communities), and they are more likely than their white and Asian peers to report giving up on STEM pursuits because of a lack of prosocial affordances. Research suggests this is the case among Latinx students 
(Torres, 2009; Villarruel et al., 2009), African American students (Harper, 2005; Martin \& Martin, 1985; Gibbs \& Griffin, 2013; Hurtado et al., 2010; Villarejo et al., 2008), Native American students (Fryberg \& Markus, 2007), and especially those who are also first-generation college students (Harackiewicz et al., 2016; Jackson et al., 2016). This is consistent with work in other motivation frameworks such as role congruity theory, which argues that the perception that STEM is incompatible with communal goals (a combination of prosocial goals and social goals, such as working collaboratively) contributes to a lack of interest in science pursuits, especially among groups who tend to be more communally-oriented (e.g., women, people of color, firstgeneration college students, and people from interdependent cultures; Boucher et al., 2017; Diekman et al., 2010).

It is important to note that all students, on average, endorse prosocial goals to some extent (Diekman et al., 2011), and all students, on average, benefit from learning about the prosocial value of course topics (Brown et al., 2015; Yeager et al., 2014). However, just as the perceived lack of prosocial value appears to contribute to a lack of diversity in STEM fields (e.g., Jackson et al., 2016), it stands to reason that emphasizing prosocial value may be particularly important for students from minoritized communities. In terms of motivation theory, this is because relevance to goals that are culturally-based and identity-relevant (such as those related to one's racial/ethnic community) is more motivationally powerful than relevance to other goals (Priniski et al., 2018). It is also important to note that endorsement of prosocial goals does not indicate a lack of endorsement of personal or self-focused goals. Indeed, research suggests that student hold both types of goals and benefit from focusing on personal and prosocial goals in combination (e.g., Tibbetts et al., 2016; Yeager et al., 2012, 2014).

In the utility-value intervention literature, Harackiewicz and colleagues (2016) conducted one of the first tests of the potential for the intervention to promote equitable outcomes. In a randomized controlled trial in college introductory biology courses, the intervention was most effective for students who were both first-generation college students and from minoritized 
communities (black, Latinx, Native American students), raising their grades in introductory college biology by about $1 / 2$ of a grade point. A follow-up study highlighted the importance of that initial performance effect in promoting students' eventual persistence in biomedical sciences majors (Hecht et al., 2019). The Harackiewicz et al. (2016) study was the first of its kind to show a positive effect for all students, on average, with a larger effect for the students with multiple marginalized identities, supporting the notion that the utility-value intervention could be used to promote equitable outcomes. The authors suggested that the intervention may have worked by helping students to connect what they were learning to their prosocial goals, because the intervention worked best for students who more strongly endorsed prosocial goals. Text analyses indicated that these students had more social content in their utility-value writing assignments as well. Thus, the researchers have begun to call for research testing new versions of the intervention that would target prosocial utility value specifically (e.g., Harackiewicz \& Priniski, 2018; Priniski et al., 2018).

Utility-value interventions for inclusivity in middle school. The factors we have reviewed thus far culminate in an imperative to provide relevant math instruction for middle school students from minoritized communities. Given (a) the systemic and structural barriers that contribute to students of color feeling excluded in math environments, (b) the importance of the middle school period for preventing declines in math motivation and promoting positive math identity development, and (c) the fact that students from minoritized communities may be turned off from math pursuits when math is not presented as relevant to prosocial goals, a prosocial utility-value intervention may be especially beneficial for promoting inclusivity in middle school math. Indeed, research suggests that Black and Latinx middle-school students develop more positive attitudes toward math when teachers emphasize the relevance of math to the real world (Dobie, 2019; Matthews, 2018). Furthermore, middle school may be an ideal time to introduce prosocial utility: middle-school students are in a developmental phase where they are moving away from self-centeredness toward social goals (Dawes, 2017), and many middle-school 
students report wanting to pursue helping-oriented careers (e.g., health careers; Prediger, 1982).

The results of Initial attempts to emphasize prosocial goals in utility-value interventions in middle school are promising. Shin and colleagues (2019) implemented a utility-value intervention in $5^{\text {th }}$ and $6^{\text {th }}$ grade science courses. Preservice teachers taught seven researcherdeveloped lessons, which emphasized the utility of science knowledge for various non-science careers popular with the students through instruction and individual and group activities. The lessons emphasized both personal utility and communal utility (i.e., usefulness for building relationships or helping others), and students completed writing activities similar to other utilityvalue interventions as well. Shin and colleagues, whose study was conducted in Korea, note that communal utility value is likely to resonate with the particular sample in their study, because prosocial, interdependent values are a strong component of East Asian cultural heritage (Hofstede \& Bond, 1988; Markus \& Kitayama, 1991). Students in a control condition experienced similar lessons and activities, but all focused on the reviewing the material rather than applying it. Shin and colleagues (2019) found that this intervention increased students' perceived personal $(d=.24)$ and communal $(d=.26)$ utility value, which were in turn associated with greater interest, intent to engage in scientific activities, and appreciation for the role of science in non-STEM careers.

In contrast to the researcher-developed lessons tested by Shin and colleagues (2019), Gray and colleagues (2020) established a research-practice partnership to develop lesson plans with teachers. They collaborated with middle school career and technical education teachers in the Southeastern United States to develop six lessons emphasizing the communal value of STEM for a STEM elective course called Design and Modeling. Each lesson was accompanied by a design-based activity (e.g., designing a prototype). Gray and colleagues argued that a focus on communal utility was needed for a race-reimaged perspective (DeCuir-Gunby \& Schultz, 2014) on relevance research. Communal values resonate with the cultural values of 
collectivity (the needs of the group supersede the needs of the individual) and cooperation (individuals benefit when the group benefits) in the black community (e.g., King \& Swartz, 2016) and with the cultural value of "familismo" (strong orientation toward one's extended family) in the Latinx community. Thus, Gray and colleagues argued that a focus on communal utility would be a point of cultural continuity (i.e., "a pattern of norms and standards that manifest in the lives of ethnic groups across locales and over time;" Gray et al., 2020, p. 2) for black and Latinx students who were the majority of students in their study. The researchers measured students' behavioral engagement and perceived communal value of the lessons over the course of the nine-week unit. Students reported higher engagement on weeks when the class lessons were more relevant for communal goals.

The purpose intervention (Yeager et al., 2014) is quite similar to the utility-value writing interventions except that rather than students reflecting on the relevance of a specific topic, the purpose intervention asks students to reflect on how working hard in school is useful for achieving "self-transcendent" or "beyond-the-self" goals, such as having a positive impact on the world or helping others. The intervention is intended to help students to see prosocial and personal relevance in even tedious schoolwork, and two studies have shown positive effects on students' grades. Yeager and colleagues (2014) found positive effects on STEM GPA for all students, on average $(d=.11)$, and especially for students with $<3.0$ prior GPA $(d=.21)$ in a primarily Asian American sample. Paunesku and colleagues (2015) found positive effects on GPA in core academic courses (math, English, science, and social studies) for students with low prior GPA (effect size information not available) in a sample from 13 schools with a range of racial/ethnic and socioeconomic compositions.

\section{Future Directions in Utility-Value Intervention Work}

The recent push to have utility-value interventions that are specifically designed to promote inclusion and equitable outcomes addresses an important criticism of utility-value research: that the vast majority of this work (especially the early work) was conducted with 
primarily white samples. Early attempts to modify the intervention for a Korean middle school sample (Shin et al., 2019) and a sample of primarily black and Latinx American students in the United States (Gray et al., 2020) are important proofs of concept for culturally-grounding the intervention. They represent a necessary expansion of important (and sometimes overlooked) features of utility-value interventions: they are intended to be student-centered in two ways. First, the utility-value intervention is student-centered in that the ultimate goal is for the students to actively participate in forging connections between course topics and their own lives whatever is important to them personally (e.g., Hulleman et al., 2010). Second, the materials used for the intervention are intended to be modified for the students and context. Even when the intervention is limited to a few writing exercises, it is important to include instructions and examples that are relevant to students and fit within the curriculum (Canning et al., 2019; Daniels \& Goegan, 2019), but this is especially the case when incorporating a directlycommunicated utility value component (Canning \& Harackiewicz, 2015).

As the field moves forward to make the intervention more culturally-grounded, researchers have an opportunity to address two additional criticisms of utility-value intervention work: that the focus on individuals ignores the systemic forces at play in determining (unequal) outcomes and that the onus is on the student to make connections, even when the curriculum may be sending messages that the material is not relevant (or at least not to all students). Recalling our definition of an inclusively relevant math environment, the new generation of utility-value interventions should aim to foster an environment that is for all students in the sense that (a) it is not against them (i.e., not exclusionary, not perpetuating stereotypes about math ability), (b) it is designed with them in mind (i.e., resonates with their lived experiences, cultural values, and background), and (c) it invites them to co-create math instruction that is meaningful for them (bringing each individual student into the process). So far, utility-value interventions have been focused on addressing the last two of these goals. However, we believe that there is an opportunity for utility-value interventions to do more by taking a critical perspective to 
address the first goal as well. Taking on this challenge would be consistent with recent calls for quantcrit methodologies, which bring a critical race perspective to quantitative research (e.g., Carter \& Hurtado, 2007; Garcia et al., 2018; Gillborn et al., 2018; Lopez et al., 2018; Stage \& Wells, 2014; Teranishi, 2007).

As researchers are making the transition to culturally-grounded interventions that incorporate a critical perspective, there is much that can be learned by looking to other fields (and especially work stemming from critical mathematics education) to learn from the great strides that have been made in strategies for making math environments and curriculum more inclusive. We focus here on one piece of the relevant literatures, teaching and learning math for social justice (TLMSJ), because we see clear synergy between TLMSJ and utility-value interventions. Importantly, these literatures are complimentary not only in that they focus on different aspects of relevance (personal vs. cultural), but also because they come out of different research traditions, with the utility-value literature containing almost exclusively quantitative research and the TLMSJ literature containing almost exclusively qualitative research. Thus the combination of the two will also move these fields toward complementary mixed-methods and quant-crit approaches in service of a more holistic approach to creating inclusively relevant math environments.

\section{Teaching and Learning Math for Social Justice}

Teaching and learning math for social justice does not rise from a single theory or theorist, and it has no single definition. It goes by many names, including social justice math pedagogies, social justice mathematics, teaching math for social justice, teaching and learning math for social justice, and critical mathematics. We use the term "teaching and learning math for social justice (TLMSJ), because it emphasizes the co-constructing roles of both teachers and students. However, we take no stance on the "correct" definition of teaching and learning math for social justice, if such a definition is even possible or appropriate (and some have certainly argued that it is not; see Powell \& Brantlinger, 2008; Wager \& Stinson, 2012). 
Larnell, Bullock, and Jett (2016) describe the broad field of teaching and learning math for social justice in the United States as having two broad branches. One branch focuses on learning math as a civil rights issue, given the access and privilege mathematical knowledge can provide, and is exemplified by Moses' work on the Algebra Project movement (e.g., Moses, 1994; Moses \& Cobb, 2001; Moses, West, \& Davis, 2009). The other branch focuses on learning math as an exercise in developing critical consciousness, as exemplified by Frankenstein's work on critical mathematical literacy (e.g., Frankenstein, 1983, 1990, 2012) and Gutstein's work on teaching mathematics for social justice (e.g., Gutstein, 2006a; Gutstein \& Peterson, 2013). Because Frankenstein's work is with adult learners, we focus here on the two of these perspectives most relevant to middle grades mathematics, those of Moses and Gutstein. In both of these perspectives, TLMSJ is about combining rigorous mathematics content with culturally-relevant, real-life contexts and applications in a way that will be empowering for students. The primary difference is that in Moses' work social justice is served in the very act of educating and in creating an activist community around math education, and in Gutstein's work social justice is served by helping students to use math to identify and rectify injustices beyond the realm of education. For the sake of this paper, we take an inclusive definition of TLMSJ to include pedagogy and practice akin to either Moses's or Gutstein's approaches, and we describe each below.

Robert Moses was a member of the Student Nonviolent Coordinating Committee (SNCC), and his work on math education reflects his roots in the Civil Rights Movement (Moses, 1994). Consistent with and informed by research suggesting that math functions as a "gateway" (e.g., Frankenstein, 1995; Skovsmose, 1994; Tate, 1995), Moses's work on the Algebra Project focuses on the development of mathematical competency (specifically, completing algebra) in middle school so that students are adequately prepared for college-preparatory math (and science) classes in high school, which subsequently open to door to higher education and careers (Moses \& Cobb, 2002). The Algebra Project has three basic goals: (a) develop 
mathematically literate, confident, motivated middle school students, (b) provide training and support for teachers to construct learning environments grounded in real-life experiences, and (c) create a broader community of parents, volunteers, and school administrators who understand the importance of math literacy to actively fight for students' right to access it. Thus, in addition to being a specific approach to mathematics instruction that centers the experiences and funds of knowledge of students of color (and especially black students), the Algebra Project is a movement to fight for equal access to quality mathematics instruction.

Gutstein (2006a, 2013) describes his approach to teaching math for social justice as based on the writings of Freire (1970/1998) and drawing significantly from the work of Frankenstein $(1983,2012)$. His pedagogy is designed to address six goals for his students, three related to social justice and three related to mathematics. Gutstein's social justice pedagogical goals are (a) reading the world with mathematics (i.e., using math to understand dynamics of power, inequity, and discrimination in the world around them), (b) writing the world with mathematics (i.e., developing a sense of agency around using math to fight for positive change in the world), and (c) developing positive cultural social identities (by centering students' languages, cultures, and communities in the instruction). His mathematical pedagogical goals are parallel to the social justice goals: (a) developing mathematical power (i.e., mastering the content and the discourse), (b) achieving "traditional" success in mathematics (i.e., passing courses, doing well on standardized tests, and subsequently accessing advanced coursework, higher education, and careers), and (c) developing a positive orientation toward mathematics (i.e., as a powerful and relevant analytic tool).

In adopting an understanding of TLMSJ that includes both Moses' and Gutstein's work, we take an approach is similar to that of Gonzalez (2009), whose definition of teaching mathematics for social justice are a hybrid of their two views having four components: (a) access to high quality instruction, (b) centering the curriculum around the experiences of minoritized communities, (c) using math as a critical tool for understanding society, and (d) 
using math as a tool to "radically reconfigure society." Notably, all of these definitions go beyond "teaching for social justice" broadly, in the sense that all teaching can be considered an exercise in social justice, because providing a good education is fundamental to the pursuit of equity. Rather, our view of TLMSJ is rooted in a sense of math education as critical, democratizing, and anti-oppressive. Indeed, TLMSJ shares many elements with culturally relevant education (e.g., critical consciousness, high standards, drawing on students' funds of knowledge, honoring their languages, cultures, etc.), but it has a particular emphasis on applying math to both understand and counteract social injustices.

Unlike the scholarship on utility-value interventions, which is dominated by experimental tests of efficacy, the scholarship on TLMSJ is dominated by case studies of teachers implementing TLMSJ in their own classrooms, with a focus on process more than outcomes. These different approaches are representative of the different types of evidence that are provided by literatures that are primarily quantitative and qualitative, respectively. In order to place these two literatures in dialog, we include research on both the process of implementing TLMSJ in middle school and the outcomes associated with it. We begin our review by recounting a case study of a TLMSJ unit, as an example of how TLMSJ plays out in a middleschool classroom. We then review the literature on the process of implementing TLMSJ, from which we draw insights on lessons learned and recommendations for teachers. Finally, we review the existing literature on the effectiveness of TLMSJ in middle school classrooms in terms of student outcomes.

\section{An Illustrative Example of Teaching and Learning Math for Social Justice}

The following example of TLMSJ was described by Jana Dean in Gustein and Peterson's (2013) book Rethinking Mathematics: Teaching Social Justice by the Numbers (Dean, 2013a). Dean used issues surrounding minimum wage and living wage to teach a multiweek unit on linear equations. She started the unit by engaging students in thinking about the issue of wages. She asked students to discuss with partners their opinions on several 
statements, such as "Those who work should be paid." and "Wages should be high enough to support a family on one income." The topic was engaging for students, because they could draw on their own families' experiences and because the various statements elicited a range of opinions (i.e., not all students agreed on the issues). She had students guess minimum wage and shared information about state and federal minimum wage. In the next class students graphed linear relationships of hourly, daily, and monthly wages for jobs that were common in their community. Students worked in groups with each group assigned a different occupation. Dean then increased the difficulty of the math by adding another variable to the linear equation, expenses. Students chose housing from the local paper's classifieds; they were assigned various regular and "surprise" expenses (e.g., flat tire, dental emergency). They used their linear equations to figure out how many hours they would need to work to pay off their expenses. They considered the local living wage and whether their jobs could support families of various sizes. Throughout this unit Dean made space for students to discuss the issues at hand and ask questions (e.g., "What's a minimum wage?" "Who decides?"), as well as including time for instruction and skills practice. At the end of the unit, students wrote individual essays using mathematical evidence to attack or defend the statement "Washington state's minimum wage is high enough." Dean reported that in future instantiations of this unit she would like to move beyond local issues and consider wages around the world, as well as consider the range of wages for different types of jobs in the United States (e.g., workers vs. CEOs or union vs. nonunion workers).

This example is illustrative for several reasons. It shares many characteristics that are common across descriptions of TLMSJ units in the literature. It involves a topic that is relevant to students' own lives and community, as well as broader social justice issues. Importantly, the topic also fostered a range of opinions, which is important for helping students to think critically about arguments on multiple sides of an issue. The unit specifically requires students to use mathematics skills to understand the issue, and then articulate an argument or opinion 
supported by math. Dean included in the unit a mix of time for focusing on math (instruction and skills practice), focusing on the broader social justice issues (large- and small-group discussions), and project work that integrated the two. The projects described in the TLMSJ literature vary in the degree to which they focus on how mathematics can be put into action in service of addressing social injustices. This project representative of the part of the spectrum that is relatively more focused on how math can be used to understand a social issues, whereas other projects incorporate more action (e.g., students presenting what they learned as educational flyers or presenting their work to the school board or city council to lobby for change). Finally Dean's book chapter is also representative of the TLMSJ literature in that she discusses both aspects of the project that seemed to work well and aspects of the project that she would change moving forward. In the spirit of the literature, we next review some recommendations for implementation of TLMSJ that arise from the literature.

\section{Implementation Recommendations for Teachers}

Much of the literature on TLMSJ is dedicated to teachers describing the various ways in which they have implemented TLMSJ in their own classrooms or teacher educators describing their students' attempts to implement TLMSJ in their preservice experiences. This literature is rich in qualitative details on the process of implementing TLMSJ, providing teachers with useful insights that we will try to relay here. These insights range from general advice about creating an environment conducive to TLMSJ, to more specific advice for teachers who want to start implementing TLMSJ, to advice for overcoming some of the challenges associated with TLMSJ.

\section{Creating an Environment Conducive to TLMSJ}

One important consideration addressed in the literature is how to foster an environment in which social justice issues can be raised and discussed in an identity-safe and educationallyproductive manner. There are several parts to this endeavor, including setting norms about discussing math as an applied field, discussing sensitive and political topics, and critically questioning everything and everyone, including the teacher. As a baseline, the classroom 
environment must support discussion of sensitive and political topics, as well as supporting constant critical thinking and questioning. This starts with a classroom culture of co-creation by students and teachers, honoring the contributions students make to the classroom through their own funds of knowledge and expertise, as well as their cultural backgrounds (e.g., Bond \& Chernoff, 2015).

A co-created classroom culture requires a rejection of what Freire $(1970 / 1998)$ called the "banking" system of education, wherein knowledge is deposited in the minds of (passive) children by their teachers, in favor of a "problem-posing pedagogy" (Freire, 1970/1998) or "pedagogy of questioning" (Gutstein, 2006b), wherein students will be comfortable questioning their own views, the views of their classmates, and even the views of the teacher. A pedagogy of questioning also supports discussion of sensitive topics, by establishing a classroom culture of open and honest inquiry (Gutstein, 2003) where critique is both expected and welcomed (Turner \& Strawhun, 2013). Finally, a pedagogy of questioning lays the foundation for broader critique of social injustices and of the ways that mathematics can be used to either sustain those injustices or rail against them (Gutstein, 2006b).

Students and teachers also need to get used to thinking and talking about mathematics as it applies to non-math topics, which may be experienced as a drastic shift if they are accustomed to skill and drill mathematics instruction (Dean, 2013a; Gutstein, 2003). Some scholars (Gregson, 2013; Gutstein, 2006a, 2006b) report that a curriculum derived from NCTM's $(1989,2000)$ Standards can help to lay a foundation for TLMSJ. For example, Gutstein's school used Mathematics in Context, and he argued that having this curriculum, which was the basis of $75-80 \%$ of the instructional time in his classes, helped to establish the conditions for TLMSJ in three ways. First, students became accustomed to seeing math presented in real-world scenarios (even if they were hypothetical and not particularly relatable, at least according to his students; Gutstein, 2006a). Second, the curriculum is conceptually based rather than procedure-oriented and is built on the philosophy of students as creators of the mathematics 
who should be encouraged to analyze problems from multiple perspectives. These features of the curriculum are far more compatible with TLMSJ than text-driven, teacher-centered approaches. Finally, Gutstein argued that because application of mathematics to social justice issues requires a strong mathematical knowledge base, TLMSJ was more successful because it was paired with a curriculum that functioned well in that context. Thus, one way to lay the foundation for TLMSJ is to seek out curricula that are student-centered, conceptually based, and contextualized, or seek out strategies to incorporate these characteristics into the whatever curriculum they are using.

\section{Getting Started}

Several scholars noted that teachers who want to implement TLMSJ can start slowly, by integrating one or more lessons from the existing literature. Gutstein and Peterson's (2013) book and the accompanying website are designed to provide a guide for teachers and contain many examples of TLMSJ projects. A range of strategies can be used for integrating the TLMSJ project into a course. Garii \& Rule (2009) conducted a qualitative analysis of social justice lessons taught by student teachers in elementary- and middle-school math and science classes. They observed four approaches to incorporating social justice into a single lesson: data analysis (having students collect and/or work w/ data), discussion (of readings, videos), modeling (e.g., testing for gender differences in class and comparing w/ statewide scores), and library/internet research (e.g., look up data on women and people of color in math fields). Simic-Muller (2015) suggested starting with existing word problems in the textbook, assessing them as to whether they (a) represent something that people would want or need to answer in their daily lives or (b) gives students new and relevant information about the world they live in, and if at least one of those is true, adapt the existing textbook problems by replacing textbook numbers with real data. Simic-Muller also recommended having students create a written arguments based on the information in the problem, giving them practice in using math to defend a position. 
In choosing topics for TLMSJ units, many scholars suggested starting with topics that were directly relevant to students or their communities, rather than trying to make connections at a national or international level right away (e.g., Garii \& Rule, 2009; Leonard et al., 2010; Turner \& Strawhun, 2013). Choosing a topic of greater relevance to students' lived experiences capitalizes on students' funds of knowledge (e.g., Aguirre \& Zavala, 2013a; Dean, 2013a), and likely makes the topic more interesting and engaging for them as well. This can be accomplished with a combination of getting to know the students and community well (Bartell, 2013; Leonard et al., 2010) and providing space for create spaces for students to make meaningful choices about topics or how they want to investigate the topics (Turner, 2003). For example, Hendrickson (2015) selected a topic that was currently being debated in the community (fracking), the class worked together to make a master list of questions they had about the topic, discussed which ones math could be used to answer, and then chose topics individually from the "approved" master list. Once the norm of discussing mathematics applications has been established and students have developed a sense of competence in discussing the social justice relevance of mathematics, teachers may wish to branch out into broader social justice issues.

Equally as important as selecting a social justice topic is matching that that topic to the mathematics curriculum, as the two must be well-integrated if the TLMSJ unit is to serve both mathematics and social justice goals (e.g., Gutstein, 2003). In their analysis of social justice lessons taught by student teachers, Garii \& Rule (2009) observed that many student teachers struggled to balance math and social justice goals, framing content in social justice topics without actually delving into the social justice issues, or focusing on the social justice issue without dedicating enough time to make sure the students understood the math content. In fact, balancing math and social justice goals was a theme in much of the literature we reviewed (e.g., Alexander et al., 2019; Appelbaum \& Davila, 2007; Bartell, 2013; Gregson, 2013; Gutstein, 2006a; Turner, 2003; Turner \& Strawhun, 2013). 
Although we have focused thus far on aspects of TLMSJ that are common across different conceptualizations in the literature, it is important to note that some conceptualizations of TLMSJ go a little further. For example, some scholars argue that teachers who implement TLMSJ should establish political relationships with their students (Gutstein 2006, 2008; Moses \& Cobb, 2001, 2002). This kind of relationship is perhaps most evident In Moses and Cobb's (2001, 2002) Algebra Project, which includes engaging in community activism to demand equal educational opportunities. However, it is also evident in the work of Gutstein, who argues that political teacher-student relationships "include taking active political stands in solidarity with students and their communities about issues that matter. Political relationships also entail teachers sharing political analyses with students as much as possible. Finally, they include talking with students about social movements, involving students themselves in studying injustice, and providing opportunities for them to join in struggles to change the unjust conditions" (Gutstein, 2006a, pp. 132-133). For example, after Gutstein taught a TLMSJ unit in the context of a proposed new luxury apartment building in the neighborhood, Gutstein went with several interested students to a city hearing, and although he had not intended to speak, he agreed to when his student insisted. This kind of relationship, though challenging to navigate, can be understood in the sense that a teacher who is going to push students to develop agency in addressing social injustice must also be willing to act on their own agency.

Another point of contention among some TLMSJ scholars is the extent to which TLMSJ is sufficiently engaging in critique of mathematics itself. In particular, Nolan (2009) has argued that "What often fails to become illuminated in the well-intentioned 'statistics and figures' approach to the marriage of social justice and mathematics [which Nolan argues is teaching dominant mathematics while using social justice examples] is the question of "why do we teach what we teach?"' In other words, Nolan is concerned that, in practice, the "critical" piece of TLMSJ has been trained only on critique of social issues and not on critique of the role of math content and context (what we teach and how we teach it) in reinforcing the status quo. 


\section{Overcoming Challenges}

TLMSJ is outside a lot of teachers' (and students') comfort zone, in terms of how they are used to teaching and learning mathematics, and it is important to acknowledge that drawing connections between math and social justice issues is no small feat. Indeed, making meaningful connections to social justice topics requires a deeper understanding of the mathematics content and an understanding of social issues (Barton, 1998; Barton et al., 2008; Garii \& Rule, 2009; Gutstein, 2006a; 2007). Furthermore, many of the skills that teachers have developed for enacting mathematics instruction do not transfer seamlessly to facilitating discussions on sensitive topics (e.g., Harrison, 2015). As Leonard and colleagues (2010) noted, teachers should not be judged (nor judge themselves) on their first attempts to enact TLMSJ. It is a process, requiring constant reflecting and active co-creating with students (e.g., Bond \& Chernoff, 2015). In fact, most of the articles we reviewed had commentary on how teachers could improve the activities in future iterations. Engaging in the scholarship of TLMSJ is one way that all teachers can collectively benefit from the challenges and successes of their peers. To that end, we review some of the challenges that were mentioned in the TLMSJ literature and describe scholars' responses to these challenges.

One of the main concerns raised by teacher candidates who were being trained on social justice pedagogies was that they anticipated pushback from parents or administrators (e.g., Appelbaum \& Davila, 2007). These concerns are not unfounded; Gutstein (2006c) wrote candidly about his mixed experiences with administrators. However, TLMSJ is becoming a more common approach, including in teacher education programs and professional organizations (e.g., Alexander et al., 2019; Cochran-Smith et al., 2009). Garii and Rule (2009) recommended emphasizing with stakeholders how the TLMSJ approach helps students to make personally meaningful connections that will improve their learning. Gutstein and Peterson (2013) recommended emphasizing ways in which TLMSJ adheres to educational standards: "One 
approach is to survey your state's math standards (or the national standards) and to find references 'critical thinking' or 'problem-solving' and use those to explain your curriculum. Also, the NCTM clearly states that 'mathematical connections' between curriculum and students' lives are important" (p. 5).

Teachers who implement TLMSJ may also worry that the emphasis on injustices that are not easily changed will result in students feeling hopeless or disempowered (e.g., Gutstein, 2003, 2007; Simic-Muller et al., 2015). Turner (2003) noted that students felt hopeful when they were able to link their own struggles to those of others like them who had faced similar challenges and overcame them. Gutstein (2007) suggested making connections to ongoing social movements in the community, so that students can benefit from seeing responses to social injustice in action, especially if they can relate to the social justice actors (people in their community, people who faced similar challenges). These issues may be of particular concern in contexts where students are experiencing severe injustice in their daily lives. Kokka (2019) conducted a study in a racially diverse Title I school in a neighborhood facing severe economic, environmental, and education challenges and high levels of violence. Kokka noted that teachers needed to take a healing-informed approach combining trauma-informed care, radical healing, and TLMSJ so as to not re-traumatize students for whom injustices hit too close to home.

Finally, several scholars noted concerns that teachers may have about facilitating classroom discussions. For example, Harrison (2015) reported that "As I engaged in the unit, I found myself becoming uncomfortable and in some ways struggling with how to facilitate a conversation with the students in the class. I felt fairly confident in my ability to help students with mathematical misunderstandings but soon discovered that there was a difference in the skillsets needed to facilitate conversations about social justice" (p. 8). SimicMuller (2015) advised that teachers should not avoid controversial issues, but should keep the discussions close to the mathematics as much as possible, and ensure that the discussions are respectful. In particular, some scholars have noted that discussions of disparities (e.g., unequal 
distribution of resources) can slip into victim blaming, language focused on personal responsibility rather systems of oppression, and/or reinforcement of stereotypes or one's own privilege (e.g., Esmode, 2014; Lim, 2016). Teachers will need to nimbly steer the conversation to critical analysis of those statements, calling into question why someone might think or say something stereotypic and encouraging students to think about how they might use math to check their assumptions/stereotypes. This highlights again the importance of having a pedagogy of questioning so that when the discussion may go astray it will be normative for the teacher (or better yet a student) to raise questions.

Issues surrounding the dynamics of classroom discussion may be particularly challenging for white teachers who are teaching students of color (e.g., Gregson, 2013; Gutstein, 2004). Although more work is especially needed in this area, Gutstein (2004) provided some questions for white educators to consider: "Why should students of color, who know firsthand the pain and horror of racism, necessarily share their thoughts, feelings, and ideas in a classroom with a white teacher? What difficulties exist when teaching about racism across color lines, given sociopolitical and cultural power differentials in a racist society? Since my students have direct experience with racism, and my knowledge is more analytical, historical, and observational, how do we meet in mutual respect to deepen our collective understanding of the impact of racism and how to fight better against it? How do I better understand how my students perceive and experience racism and other forms of discrimination so that I can create opportunities for them to better comprehend the nature of these injustices -- all while teaching mathematics in a high-stakes, urban school district focused on "accountability." regimentation, and discipline?" (p. 32).

\section{The Impact of Teaching and Learning Math for Social Justice on Student Outcomes}

It is important to note that very few studies on TLMSJ are presented as tests of effectiveness. As noted above, the TLMSJ literature is primarily focused on the process of implementing social justice practices and pedagogies as rooted in the theoretical and research 
traditions of critical mathematics education and culturally relevant education. However, there are a number of studies that report a range of outcomes corresponding to the various goals of TLMSJ, which include mastery of the mathematics content as well as development of sociopolitical consciousness, mathematical power, sense of agency, and positive attitudes about mathematics). Overall, the existing studies indicate that TLMSJ can support achievement of these goals. Evidence of gains includes teacher and researcher observations, student surveys and interviews, and pre/post assessments.

In terms of increasing sociopolitical consciousness, Gutstein $(2004,2013)$ reported that student essays at the end of TLMSJ units reflected increased awareness and critical analysis of social justice issues. For example, in his honors math class of primarily Latinx students from families experiencing economic disadvantage, one student wrote, "From this project I learned that you should question everything... That's what I did" (Gutstein, 2013, p. 66). Dean (2013a) surveyed students months after the wages and linear equations unit described above. Students reported that the unit had made them more aware of issues surrounding social class.

Studies also suggest that TLMSJ can support students' sense of agency and positive attitudes toward mathematics. Sims (2016) reported that African American middle-school boys in the MAN UP program, which met every other Saturday during school year to learn about computer science, math, and rhetorical analysis of manhood, was associated with an increase in identification with STEM from the beginning of the program to the end. Surveys also revealed that $16 / 17$ students had increased confidence in math over the course of the program. Turner and Strawhun (2013; Turner, 2003) used TLMSJ to teach a class of primarily African American, Dominican, and Puerto Rican students about measurement, area, fractions, and ratios. The teacher observed that students who were not typically engaged in class were engaged during this unit, and attributed that engagement to the fact that the topic (overcrowding at their school) was personally meaningful for the students. Lim (2016) reported on interviews with a sample of primarily black $8^{\text {th }}$-grade students whose families were experiencing economic disadvantage. 
They completed a TLMSJ project comparing the proportions of vacant lots and basketball courts across neighborhoods in their city. The interviews revealed a sense of empowerment after the TLMSJ project; students felt they could use math to understand social justice issues and persuade others of their position. Denny (2013) reported that when students displayed their work (posters) from the TLMSJ unit on percent change in the representativeness of congress and a topic of the students' choosing, the experience of having the work admired by teachers and peers helped them to see the importance and impact of their new mathematical skill.

TLMSJ can also support development of mathematical power and mastery of mathematical content. Sims (2016) found that the MAN UP program increased scores on a math concept inventory from the beginning of the program to the end. Aguirre \& Zavala (2013b) used TLMSJ to teach proportional reasoning in a summer math program attended by primarily African American, Latinx, Vietnamese, and East African immigrant youth in the summer after 8th grade. They found that whereas students had been struggling with traditional proportional reasoning tasks, when the math team created a problem that would be more accessible and relevant, centering fairness, they observed improvements in students' understanding and proportional reasoning skills. Similarly, when Dean (2013b) used TLMSJ to teach about square roots by examining the area of students' usable desk space and the area of homes in different parts of the world, $8^{\text {th }}$-grade students showed greater mastery of square roots on the exam than in previous years.

Although much of the literature on TLMSJ reports on the impact of specific units or projects, a few studies report on the impact of TLMSJ when implemented consistently throughout the school year. Moses and $\operatorname{Cobb}(2001,2002)$ have reported comparisons between students who receive mathematics instruction through the Algebra Project and students who attend similar schools that are not part of the Algebra Project. In Cambridge, Massachusetts, $92 \%$ of Algebra Project graduates enrolled in upper-level math classes in $9^{\text {th }}$ grade, a rate that was about twice that of their peers. In San Francisco, $56 \%$ of black Algebra Project students 
enrolled in college-preparatory classes, compared to $24 \%$ of a demographically similar group in the district. Finally, in one county in Mississippi, Algebra Project students scored well above the state mean, despite being one of the communities facing the greatest economic challenges in the state. These results, which represent the only study of TLMSJ with a comparison group, suggest that students are achieving mastery of the mathematical content and developing mathematical power. In another study, Gutstein (2003) reported on two years of TLMSJ with an honors-track math class of $7^{\text {th }}$ (and then $8^{\text {th }}$ ) grade students. The students were primarily Latinx youth from families experiencing economic disadvantage, about half of whom came from immigrant families. Student surveys revealed that 22/25 students changed their views of math, and 20/23 reported being better able to understand the world using math. Gutstein also reported that $27 / 28$ students demonstrated mathematical power in terms of mastery of course concepts. Finally, Gutstein observed that students engaged in deeper questioning and reasoning over time, which may suggest development of sociopolitical consciousness.

In sum, the existing literature suggests that TLMSJ can support positive outcomes for mathematics students, in terms of helping students achieve "traditional" academic success (e.g. mastery the content, performing well on standardized tests), as well as making gains toward the other goals of TLMSJ (e.g., development of sociopolitical consciousness, sense of agency, and positive attitudes toward mathematics). Although very few of these studies were undertaken as tests of the effectiveness of TLMSJ, the fact that the existing literature points to this range of benefits is important. It suggests that TLMSJ can be implemented without significant tradeoffs in student achievement (as narrowly measured by the testing and accountability structures), which is a necessary goal in students' current reality of mathematics as a gatekeeper. As Gutstein (2006a) put it, "Although I put little stock in these [standardized] tests to assess what students genuinely know or their mathematical power, they indicate certain competencies and clearly have strong impact on students' lives" (p. 118). 


\section{Points of Synergy}

Although utility-value interventions and TLMSJ have thus far been developing in separate siloes, we see several points of synergy between them. In the case of utility-value interventions, the focus has been on helping students to find personal value and meaning in their schoolwork, but the field is beginning to integrate principles of cultural relevance as it moves toward adapting the intervention for students from minoritized communities. Recent implementations of the utility-value intervention (e.g., Gray et al., 2020) have the specific goal of helping students to see how math might be used in the pursuit of prosocial goals. In the case of TLMSJ, the focus has been on creating a culturally relevant environment in which students learn how math can be used to both understand and resist social injustices, with the idea that this will make math more personally meaningful for students. Thus, although the approaches are quite different, the two literatures both have goals of making learning personally meaningful for students and helping students to see how math can be used to pursue prosocial goals. In fact, our review of TLMSJ projects in the literature revealed quite a few that had elements related to utility-value interventions, especially in efforts to make the projects more personally meaningful.

Dean's (2013) project about linear equations and wages, which was described above, was made more personally relevant to students by making use of actual wage data and cost of living from students' own communities. It also included an individual writing assignment where students used math to articulate and defend their personal viewpoint. This writing assignment echoes of utility-value writing assignments, although the students were not given the option to choose the topic. Similarly, Gutstein's (2006) approach to TLMSJ included individual or group write-ups in which students had to express their own views on the social issue, as well as weekly journal assignments for students to reflect on what they were learning.

Hendrickson (2015) conducted a TLMSJ project related to mathematical modeling. She chose a topic that was a matter of current debate in the community (fracking), and the students generated a list of questions they had, discussed whether/how math could be used to answer 
the question, and then students picked a question to answer. This is again very similar to a utility-value writing assignment, which would ask students to choose a topic and write about how math was useful for that topic. This project goes a step further than a writing assignment in that students had to implement the utility: use math to answer their question.

Turner and Strawhun (2013; Turner, 2003) conducted a TLMSJ project to teach measurement, area, fractions, and ratios. The teacher began by asking students to list issues about the school or community that concerned them, and chose the broad project topic from among the issues that appeared repeatedly on that list and were amenable to the mathematics unit (overcrowding in their school). The students later worked in small groups and developed their own questions relevant to the broader topic they'd been working on as a whole class. This project required students to both implement the utility in terms of using math to answer their question but also required students to use math to implement their social justice goal: they used their projects to educate the school community about the overcrowding issue, presented their results to the school board, and shared their data with the district.

As these examples illustrate, there is already a lot of overlap in the goals and features of utility-value interventions (especially as the field is moving toward culturally-grounded and prosocially-oriented adaptions of the intervention) and TLMSJ projects. As Turner and Strawhun (2013) noted, the increased student engagement during their TLMSJ project may be attributable to allowing students to choose topics that were so personally relevant, which speaks to the potential of incorporating more personal relevance into TLMSJ. Thus we see a lot that can be learned by utility-value researchers from the work that has been done by TLMSJ scholars; if they are moving toward combining personal, cultural, and prosocial value, there is already an entire field doing that work, and we encourage utility-value researchers not to reinvent the wheel. Furthermore, as the utility-value researchers are moving toward using the intervention to address educational disparities, we believe that it is important to adopt a critical lens; here too, scholarship on TLMSJ can provide valuable insights. 
We also see value in TLMSJ researchers learning from the work on utility-value interventions. Many scholars have noted the importance of helping students get used to thinking and talking about mathematics as it applies to non-math topics, as a foundation for thinking about math as it applies to social justice. Gregson (2013) and Gutstein (2006a, 2006b) have discussed the value of using a curriculum like Mathematics in Context, but the real-world examples were not necessarily resonant for students, and not all teachers have a curriculum that emphasizes relevance. Implementation of utility-value activities, such as those designed by Hulleman and colleagues (Motivate Lab, 2018) could be a useful strategy for establishing that foundation, while increasing personal relevance. Scholars have also noted concern about overwhelming students with large, intractable social problems that students may feel helpless to combat (e.g., Gutstein, 2003, 2007; Simic-Muller et al., 2015); giving students opportunities to think about small ways that math is relevant to their daily lives can help to bridge that gap and provide students with a sense of agency before (and in addition to) developing agency for addressing larger societal problems. Furthermore, relating the content to students' own lives helps to draw on their funds of knowledge and engage them in the co-creation of knowledge in the classroom.

Finally, as Garii and Rule (2009) recommended, explaining the TLMSJ approach in terms of helping students to make personally meaningful connections that will improve their learning can help teachers to assuage concerns of parents or administrators about the TLMSJ approach. Utility-value research can be useful for teachers in this regard, both because there is a large literature demonstrating the relation of relevance to positive student outcomes and because this evidence comes from a different research tradition. Inevitably as teachers navigate the politics of what is taught and how, there will be a diversity of opinions on what constitutes strong evidence for an instructional approach. With the TLMSJ literature being primarily qualitative and the utility-value intervention literature being primarily quantitative, teachers will 
benefit from the ability to draw on both sets of evidence to make their case. And we would posit that this case will only get stronger as the literatures begin to build upon each other.

\section{Directions for Future Research}

As these fields move forward we see great opportunities for these two rich but disparate literatures to build upon each other. For example, the utility-value intervention literature has been largely focused on student outcomes, whereas the TLMSJ literature has been largely focused on the experience of teachers who implement TLMSJ. The focus on students vs. teachers need not be mutually exclusive. Teacher-focused research would help make utilityvalue interventions more accessible to teachers, and more student-focused research would help to establish a broader evidence base for the effectiveness of TLMSJ. Relatedly, the samples for these two literatures are quite different, with most of the utility-value work being done with primarily white samples (although this has been changing in recent years) and the TLMSJ work being done with primarily students of color. Both literatures would benefit from a better understanding of how these approaches work across contexts and especially in contexts that are very racially, culturally, and socioeconomically diverse.

Leveraging the strengths of both literatures also calls for methodological advancements. The use of mixed-methods and especially quantcrit approaches can draw on strengths of both literatures and expand the evidence base for both. Ultimately we believe that a combination of methods will result in the most convincing research base for the wide range of stakeholders concerned with education reform (students, parents, teachers, school and district administrators, local and national policy makers).

Combining two disparate literatures is no small task. Future research will need to include collaborations among scholars of utility value and TLMSJ, as well as research-practice partnerships with middle school teachers. We humbly suggest the following possible starting points, all of which might be undertaken with quantcrit methods or mixed methods. 
a) Studies of existing utility-value intervention activities that are focused on teachers' experiences with implementation and studies of existing TLMSJ activities that are focused on student outcomes, such as engagement and mastery of the content

b) Design-based research with focus groups of teachers and students to create lessons that would be both personally and culturally relevant

c) Comparisons of TLMSJ activities with varying levels of focus on personal relevance

d) Comparisons of utility-value activities with varying levels of focus on social justice issues

e) Research examining the factors that contribute to a classroom environment conducive to discussions of personal and cultural relevance and social justice issues

\section{Conclusions}

We have held that in order for a math classroom to be inclusively relevant, it needs to be for all students in the sense that (a) it is not against them (i.e., not exclusionary, not perpetuating stereotypes about math ability), (b) it is designed with them in mind (i.e., instruction resonates with their lived experiences, cultural values, and background), and (c) it invites them to co-create math instruction that is meaningful for them (bringing each individual student into the process). Our review of the literatures on utility-value interventions and teaching and learning mathematics for social justice suggest that these two literatures could be complementary and even synergistic in promoting a holistic approach to creating inclusively relevant math learning environments. They share many of the same goals, and as utility value work makes a needed shift toward adopting critical and cultural lenses, utility-value researchers will benefit from the great work that has been done on TLMSJ. Likewise, we believe that utilityvalue activities can help to establish an environment in which students see math as personally meaningful, both in their own daily lives and in addressing social injustices. By leveraging quantcrit methods and mixed methods to bridge the two research literatures, researchers can establish a strong evidence base for approaches that make math learning environments relevant and inclusive for all students. 


\section{References}

Aguirre, J. M., \& Zavala, M. del R. (2013a). Making culturally responsive mathematics teaching explicit: A lesson analysis tool. Pedagogies: An International Journal, 8, 163-190.

Aguirre, J. M., \& Zavala, M. del R. (2013b). When equal isn't fair: Using ratios to scale up mathematical arguments. In E. Gutstein \& Peterson, B. (Eds.), Rethinking mathematics: Teaching social justice by the numbers (2nd ed., pp. 115-121). Rethinking Schools, Ltd.

Akcaoglu, M., Rosenberg, J. M., Ranellucci, J., \& Schwarz, C. V. (2018). Outcomes from a selfgenerated utility value intervention on fifth and sixth-grade students' value and interest in science. International Journal of Educational Research, 87, 67-77. https://doi.org/10.1016/j.ijer.2017.12.001

Alexander, N. N., Teymuroglu, Z., \& Yerger, C. R. (2019). Critical conversations on social justice in undergraduate mathematics. PRIMUS, 29, 396-419.

https://doi.org/10.1080/10511970.2018.1530704

Anderson, S. E. (1997). Worldmath curriculum: Fighting Eurocentrism in mathematics. In A. B. Powell \& M. Frankenstein (Eds.), Ethnomathematics: Challenging Eurocentrism in mathematics education (pp. 291-306). State University of New York Press.

Appelbaum, P., \& Davila, E. R. (2007). Math education and social justice: Gatekeepers, politics and teacher agency. Philosophy of Mathematics Education Journal, 22, 1-23.

Aronson, B., \& Laughter, J. (2016). The theory and practice of culturally relevant education: A synthesis of research across content areas. Review of Educational Research, 86, 163206. https://doi.org/10.3102/0034654315582066

Bartell, T. G. (2013). Learning to teach mathematics for social justice: Negotiating social justice and mathematical goals. Journal for Research in Mathematics Education, 44, 129-163. https://doi.org/10.5951/jresematheduc.44.1.0129

Barton, A. C. (1998) Teaching science with homeless children: pedagogy, representation, and identity, Journal of Research in Science Teaching, 35, 379- 94. 
Barton, A. C., Tan, E., \& Rivert, A. (2008). Creating hybrid spaces for engaging school science among urban middle school girls. American Educational Research Journal, 45, 68-103.

Bond, G., \& Chernoff, E. J. (2015). Mathematics and social justice: A symbiotic pedagogy. Journal of Urban Mathematics Education, 8, 24-30.

Boucher, K. L., Fuesting, M. A., Diekman, A. B., \& Murphy, M. C. (2017). Can I work with and help others in this field? How communal goals influence interest and participation in STEM fields. Frontiers in Psychology, 8, 901. https://doi.org/10.3389/fpsyg.2017.00901

Brady, L. M., Germano, A. L., \& Fryberg, S. A. (2017). Leveraging cultural differences to promote educational equality. Current Opinion in Psychology, 18, 79-83. https://doi.org/10.1016/j.copsyc.2017.08.003

Brisson, B. M., Dicke, A.-L., Gaspard, H., Häfner, I., Flunger, B., Nagengast, B., \& Trautwein, U. (2017). Short intervention, sustained effects: Promoting students' math competence beliefs, effort, and achievement. American Educational Research Journal, 54, 10481078. https://doi.org/10.3102/0002831217716084

Brophy, J. (1999). Toward a model of the value aspects of motivation in education: Developing appreciation for particular learning domains and activities. Educational Psychologist, 34, 75-85.

Brown, E. R., Smith, J. L., Thoman, D. B., Allen, J. M., \& Muragishi, G. (2015). From bench to bedside: A communal utility value intervention to enhance students' biomedical science motivation. Journal of Educational Psychology, 107, 1116-1135. https://doi.org/10.1037/edu0000033

Canning, E. A., \& Harackiewicz, J. M. (2015). Teach it, don't preach it: The differential effects of directly communicated and self-generated utility-value information. Motivation Science, 1, 47-71. https://doi.org/10.1037/mot0000015 
Canning, E. A., Priniski, S. J., \& Harackiewicz, J. M. (2019). Unintended consequences of framing a utility-value intervention in two-year colleges. Learning and Instruction, 62, 3748. https://doi.org/10.1016/j.learninstruc.2019.05.001

Carter, D. F., \& Hurtado, S. (2007). Bridging key research dilemmas: Quantitative research using a critical eye. New Directions for Institutional Research, 133, 25-35. https://doi.org/10.1002/ir.202

Covarrubias, R., Herrmann, S. D., \& Fryberg, S. A. (2016). Affirming the interdependent self: Implications for Latino student performance. Basic and Applied Social Psychology, 38, 47-57. https://doi.org/10.1080/01973533.2015.1129609

Daniels, L. M., \& Goegan, L. D. (2019). Applying Utility-Value Writing Prompts to Science Education. Alberta Science Education Journal, 46, 22-27.

Dawes, M. (2017). Early adolescents' social goals and school adjustment. Social Psychology of Education, 20, 299-328.

Dean, J. (2013a). Living algebra, living wage. In E. Gutstein \& Peterson, B. (Eds.), Rethinking mathematics: Teaching social justice by the numbers (2nd ed., pp. 67-77). Rethinking Schools, Ltd.

DeCuir-Gunby, J. T., \& Schutz, P. A. (2014). Researching race within educational psychology contexts. Educational Psychologist, 49, 244-260. https://doi.org/10.1080/00461520.2014.957828.

Denny, F. (2013). Teaching percent change + social justice = opportunity for deep mathematical discussion. In E. Gutstein \& Peterson, B. (Eds.), Rethinking mathematics: Teaching social justice by the numbers (2nd ed., pp. 67-77). Rethinking Schools, Ltd.

Diekman, A. B., Brown, E. R., Johnston, A. M., \& Clark, E. K. (2010). Seeking congruity between goals and roles: A new look at why women opt out of science, technology, engineering, and mathematics careers. Psychological Science, 21, 1051- 1057. https://doi.org/10.1177/095679761037 7342 
Diekman, A. B., Clark, E. K., Johnston, A. M., Brown, E. R., \& Steinberg, M. (2011). Malleability in communal goals and beliefs influence attraction to STEM careers: Evidence for a goal congruity perspective. Journal of Personality and Social Psychology, 101, 902-918. https://doi.org/10.1037/a0025199

Dobie, T. E. (2019). A sociocultural examination of utility value in mathematics: The role of interdependence in middle school students' perceptions of usefulness. In M. S. Hannula, G. C. Leder, F. Morselli, M. Vollstedt, \& Q. Zhang (Eds.), Affect and Mathematics Education (pp. 67-88). Springer International Publishing. https://doi.org/10.1007/978-3030-13761-8_4

Dover, A. G. (2009). Teaching for social justice and k-12 student outcomes: A conceptual framework and research review. Equity \& Excellence in Education, 42, 506-524. https://doi.org/10.1080/10665680903196339

Duffin, L. C., Starling, M. P., Day, M. M., \& Cribbs, J. D. (2016). The effects of a consumer chemistry intervention on urban at-risk high school students' performance, utility value, and intentions to pursue STEM: Making chemistry relevant. School Science and Mathematics, 116, 356-365. https://doi.org/10.1111/ssm.12188

Durik, A. M., Schechter, O. G., Noh, M., Rozek, C. S., \& Harackiewicz, J. M. (2015). What if I can't? Success expectancies moderate the effects of utility value information on situational interest and performance. Motivation and Emotion, 39, 104-118.

Dweck, C. S., \& Elliott, E. S. (1983). Achievement motivation. In E. M. Hetherington (Ed.), Handbook of child psychology: Vol. 4. Socialization, personality, and social development (4th ed., pp. 643-691). Wiley.

Dweck, C. S., \& Master, A. (2009). Self-theories and motivation: Students' beliefs about intelligence. In K. R. Wentzel \& A. Wigfield (Eds.), Handbook of motivation at school (pp. 123-140). Routledge. 
Eccles, J. S. (2009). Who am I and what am I going to do with my life? Personal and collective identities as motivators of action. Educational Psychologist, 44, 78_89. doi:10.1080/00461520902832368

Eccles, J. S., Adler, T. F., Futterman, R., Goff, S. B., Kaczala, C. M., Meece, J. L., \& Midgley, C. (1983). Expectations, values, and academic behaviors. In J. T. Spence (Ed.), Perspective on achievement and achievement motivation (pp. 75-146). W. H. Freeman.

Eccles, J. S., \& Wigfield, A. (2000). Expectancy-value theory of achievement motivation. Contemporary Educational Psychology, 25, 68-81. https://doi.org/10.1006/ceps.1999.1015

Esmonde, I. (2014). "Nobody's rich and nobody's poor ... it sounds good, but it's actually not": Affluent students learning mathematics and social justice. The Journal of the Learning Sciences, 23, 348-391. https://doi.org/10.1080/10508406.2013.847371

Frankenstein, M. (1983). Critical Mathematics Education: An Application of Paulo Freire's Epistomology. Journal of Education, 165, 315-339.

Frankenstein, M. (1990). Incorporating Race, Gender, and Class Issues into a Critical Mathematica Literacy Curriculum. The Journal of Negro Education, 59, 336. https://doi.org/10.2307/2295568

Frankenstein, M. (1995). Equity in mathematics education: Class in the world outside the class. In W. G. Secada, E. Fennema, \& L. Byrd (Eds.), New directions for equity in mathematics education (pp. 165-190). Cambridge University Press.

Frankenstein, M. (2012). Beyond Math Content and Process: Proposals for Underlying Aspects of Social Justice Education. In A. A. Wager \& D. W. Stinson (Eds.), Teaching mathematics for social justice: Conversations with educators (pp. 49-62). National Council of Teachers of Mathematics.

Freire, P. (1970/1998). Pedagogy of the oppressed. (M. B. Ramos, Trans.). Continuum. 
Fryberg, S. A., \& Markus, H. R. (2007). Cultural models of education in American Indian, Asian American and European American contexts. Social Psychology of Education: An International Journal, 10, 213-246. https://doi.org/10.1007/s11218-007-9017-z

Garcia, N. M., López, N., \& Vélez, V. N. (2018). QuantCrit: Rectifying quantitative methods through critical race theory. Race Ethnicity and Education, 21, 149-157. https://doi.org/10.1080/13613324.2017.1377675

Garii, B., \& Rule, A. C. (2009). Integrating social justice with mathematics and science: An analysis of student teacher lessons. Teaching and Teacher Education, 25, 490-499. https://doi.org/10.1016/j.tate.2008.11.003

Gaspard, H., Dicke, A., Flunger, B., Brisson, B., Hafner, I., Nagengast, B., \& Trautwein, U. (2015). Fostering adolescents' value beliefs for mathematics with a relevance intervention in the classroom. Developmental Psychology, 51, 1226-1240. https://doi.org/10.1037/dev0000028

Gay, G. (2000). Culturally responsive teaching theory, research, and practice. Teachers College Record.

Gibbs, K. D., \& Griffin, K. A. (2013). What do I want to be with my PhD? The roles of personal values and structural dynamics in shaping the career interests of recent biomedical science PhD graduates. CBE- Life Sciences Education, 12, 711-723. https://doi.org/10.1187/cbe.13-02-0021

Gillborn, D., Warmington, P., \& Demack, S. (2018). QuantCrit: Education, policy, 'big data' and principles for a critical race theory of statistics. Race Ethnicity and Education, 21, 158179. https://doi.org/10.1080/13613324.2017.1377417

Gonzalez, L. (2009). Teaching Mathematics for Social Justice: Reflections on a Community of Practice for Urban High School Mathematics Teacher. Journal of Urban Mathematics Education, 2, 22-51. 
González, N., Moll, L., \& Amanti, C. (2005). Funds of knowledge: Theorizing practices in households, communities, and classrooms. Erlbaum.

Gray, D. L., McElveen, T. L., Green, B. P., \& Bryant, L. H. (2020). Engaging Black and Latinx students through communal learning opportunities: A relevance intervention for middle schoolers in STEM elective classrooms. Contemporary Educational Psychology, 60, 101833. https://doi.org/10.1016/j.cedpsych.2019.101833

Gregson, S. A. (2013). Negotiating social justice teaching: One full-time teacher's practice viewed from the trenches. Journal for Research in Mathematics Education, 44, 164-198. https://doi.org/10.5951/jresematheduc.44.1.0164

Gutstein, E. (2003). Teaching and Learning Mathematics for Social Justice in an Urban, Latino School. Journal for Research in Mathematics Education, 34, 37-73. https://doi.org/10.2307/30034699

Gutstein, E. (2004). Home Buying While Brown or Black: Teaching Mathematics for Racial Justice. Learning and Teaching Mathematics, 1, 31-34.

Gutstein, E. (2006a). Reading and writing the world with mathematics: Toward a pedagogy for social justice. Routledge.

Gutstein, E. (2006b). "So one question leads to another": Using mathematics to develop a pedagogy of questioning. In N. S. Nasir \& P. Cobb (Eds.), Diversity, equity, and access to mathematical ideas (pp. 51-68). New York: Teachers College Press.

Gutstein, E. (2006c). "The real world as we have seen it”: Latino/a parents' voices on teaching mathematics for social justice. Mathematical Thinking and Learning, 8, 331-358. https://doi.org/10.1207/s15327833mtl0803_7

Gutstein, E. (2007). "And that's just how it starts": Teaching mathematics and developing student agency. Teachers College Record, 109, 420-448. 
Gutstein, E. (2008). Building Political Relationships with Students: An aspect of social justice pedagogy. In E. de Freitas \& K. Nolan, Opening the Research Text (pp. 189-219). Springer US. https://doi.org/10.1007/978-0-387-75464-2_8

Gutstein, E. (2012). Connecting Community, Critical, and Classical Knowledge in Teaching Mathematics for Social Justice. In S. Mukhopadhyay \& W.-M. Roth (Eds.), Alternative Forms of Knowing (in) Mathematics (pp. 300-311). SensePublishers. https://doi.org/10.1007/978-94-6091-921-3_15

Gutstein, E. (2013). Reading and Writing the World with Mathematics: Toward a Pedagogy for Social Justice (2nd ed.). Routledge. https://doi.org/10.4324/9780203112946

Gutstein, E., Lipman, P., Hernandez, P., \& de los Reyes, R. (1997). Culturally Relevant Mathematics Teaching in a Mexican American Context. Journal for Research in Mathematics Education, 28, 709-737. https://doi.org/10.2307/749639

Gutstein, E. \& Peterson, B. (Eds.). (2013). Rethinking mathematics: Teaching social justice by the numbers (2nd Ed.). Rethinking Schools Ltd.

Häfner, I., Flunger, B., Dicke, A.-L., Gaspard, H., Brisson, B. M., Nagengast, B., \& Trautwein, U. (2017). Robin Hood effects on motivation in math: Family interest moderates the effects of relevance interventions. Developmental Psychology, 53, 1522-1539. https://doi.org/10.1037/dev0000337

Hall, C., Dickerson, J., Batts, D., Kauffmann, P., \& Bosse, M. (2011). Are we missing opportunities to encourage interest in STEM fields? Journal of Technology Education, 23, 32-46.

Harackiewicz, J. M., Canning, E. A., Tibbetts, Y., Priniski, S. J., \& Hyde, J. S. (2016). Closing achievement gaps with a utility-value intervention: Disentangling race and social class. Journal of Personality and Social Psychology, 111, 745-765.

https://doi.org/10.1037/pspp0000075 
Harackiewicz, J. M., Durik, A. M., Barron, K. E., Linnenbrink, E. A., \& Tauer, J. M. (2008). The role of achievement goals in the development of interest: Reciprocal relations between achievement goals, interest, and performance. Journal of Educational Psychology, 100, $105-122$.

Harackiewicz, J. M. \& Priniski, S. J. (2018). Improving student outcomes in higher education: The science of targeted intervention. Annual Review of Psychology, 69, 409-435. http://dx.doi.org/10.1146/annurev-psych-122216-011725

Harper, S.R. (2005). Leading the way: Inside the experiences of high-achieving African American male students. About Campus, 10, 8-15.

Harrison, L. (2015). Teaching Social Justice through Mathematics: A Self-Study of Bridging Theory to Practice. Middle Grades Review, 1, 1-12.

Hecht, C. A., Harackiewicz, J. M., Priniski, S. J., Canning, E. A., Tibbetts, Y., \& Hyde, J. S. (2019). Promoting persistence in the biological and medical sciences: An expectancyvalue approach to intervention. Journal of Educational Psychology, 111, 14621477. https://doi.org/10.1037/edu0000356

Hendrickson, K. A. (2015). Fracking: Drilling into math and social justice. Mathematics Teaching in the Middle School, 20, 367-371.

Herrera, C. M. (2019). The effects of a utility value intervention on students' science interest and performance in a ninth grade biology class. [Doctoral dissertation, California State University, Long Beach]. ProQuest Dissertations Publishing.

Hofstede, G., \& Bond, M. H. (1988). The Confucius connection: From cultural roots to economic growth. Organizational Dynamics, 16, 5-21.

Hulleman, C. S., Durik, A. M., Schweigert, S., \& Harackiewicz, J. M. (2008). The importance of utility value in predicting interest and performance in academics and sports. Journal of Educational Psychology, 100, 398-416. https://doi.org/10.1037/0022-0663.100.2.398 
Hulleman, C. S., Godes, O., Hendricks, B. L., \& Harackiewicz, J. M. (2010). Enhancing interest and performance with a utility value intervention. Journal of Educational Psychology, 102, 880-895. http://dx.doi.org/10.1037/a0019506

Hulleman, C. S. \& Harackiewicz, J. M. (2009). Promoting interest and performance in high school science classes. Science, 326, 1410-1412. http://dx.doi.org/10.1126/science.1177067

Hurtado, S., Newman, C. B., Tran. M. C., \& Chang. M. J. (2010). Improving the rate of success for underrepresented racial minorities in STEM fields: Insight from a national project. New Directions for Institutional Research, 148, 5-15. http://dx.doi.org/10.1002/ir.357

Irvine, J. (1990). Black students and school failure: Policies, practices, and prescriptions. Praeger Publishers.

Jackson, M. C., Galvez, G., Landa, I., Buonora, P., \& Thoman, D. B. (2016). Science that matters: The importance of a cultural connection in underrepresented students' science pursuit. CBE-Life Science Education, 15:ar42, 1-12. http://dx.doi.org/10.1187/cbe.16$01-0067$

King, J. E., \& Swartz, E. E. (2016). The Afrocentric praxis of teaching for freedom: Connecting culture to learning. New York, NY: Taylor \& Francis

Kokka, K. (2019). Healing-Informed Social Justice Mathematics: Promoting Students' Sociopolitical Consciousness and Well-Being in Mathematics Class. Urban Education, 54, 1179-1209. https://doi.org/10.1177/0042085918806947

Kosovich, J. J., Hulleman, C. S.,Phelps, J., \& Lee, M. (2019). Improving algebra success with a utility-value intervention. Journal of Developmental Education, 42, 2-10.

Ladson-Billings, G. (1995). Toward a theory of culturally relevant pedagogy. American Educational Research Journal, 32, 465-491.

Ladson-Billings, G. (2006). “Yes, but how do we do it?" Practicing culturally relevant pedagogy. In J. G. Landsman \& C. W. Lewis (Eds.), White teachers' diverse classrooms: Creating 
inclusive schools, building on students' diversity, and providing true educational equity (pp. 33-46). Stylus.

Larnell, G. V., Bullock, E. C., \& Jett, C. C. (2016). Rethinking teaching and learning mathematics for social justice from a critical race perspective. Journal of Education, 196, 19-29. https://doi.org/10.1177/002205741619600104

Lazowski, R. A. \& Hulleman, C. S. (2016). Motivation interventions in education: A meta-analytic review. Review of Educational Research, 86, 602-640.

http://dx.doi.org/10.3102/0034654315617832

Lesser, L. M., \& Blake, S. (2007). Mathematical power: Exploring critical pedagogy in mathematics and statistics. Journal for Critical Education Policy Studies, 5, 349-368.

Leonard, J., Brooks, W., Barnes-Johnson, J., \& Berry, R. Q. (2010). The nuances and complexities of teaching mathematics for cultural relevance and social justice. Journal of Teacher Education, 61, 261-270. https://doi.org/10.1177/0022487109359927

Lim, V. Y. (2016). Making change with mathematics: Youth conceptions of the role of mathematics in citizenship [Doctoral dissertation, University of Pennsylvania]. ProQuest Dissertations Publishing.

López, N., Erwin, C., Binder, M., \& Chavez, M. J. (2018). Making the invisible visible: Advancing quantitative methods in higher education using critical race theory and intersectionality. Race Ethnicity and Education, 21, 180-207. https://doi.org/10.1080/13613324.2017.1375185

Maltese, A. V., \& Tai, R. H. (2011). Pipeline persistence: Examining the association of educational experiences with earned degrees in STEM among U.S. students. Science Education, 95, 877-907. https://doi.org/10.1002/sce.20441

Markus, H. R., \& Kitayama, S. (2010). Cultures and Selves: A Cycle of Mutual Constitution. Perspectives on Psychological Science, 5, 420-430. https://doi.org/10.1177/1745691610375557 
Martin, D. B., Gholson, M. L., \& Leonard, J. (2010). Mathematics as gatekeeper: Power and privilege in the production of knowledge. Journal of Urban Mathematics Education, 3, $12-24$.

Martin, J.E., \& Martin, E.P. (1985). The Helping Tradition in the Black Family and Community. National Association of Social Workers Press.

Matthews, J. S. (2018). When am I ever going to use this in the real world? Cognitive flexibility and urban adolescents' negotiation of the value of mathematics. Journal of Educational Psychology, 110, 726-746. https://doi.org/10.1037/edu0000242

Moses, R. P. (1994). An alternative approach: The Algebra Project. Journal of Mathematical Behavior, 13, 105-106.

Moses, R. P., \& Cobb, C. E. (2001). Organizing algebra: The need to voice a demand. Social Policy, 31, 4-12.

Moses, R. P., \& Cobb, C. E. (2002). Radical Equations: Civil Rights from Mississippi to the Algebra Project. Boston, MA: Beacon Press.

Moses, R., West, M. M., \& Davis, F. E. (2009). Culturally responsive mathematics education in the Algebra Project. In B. Greer, S. Mukhopadhyay, A. B. Powell, \& S. Nelson-Barber (Eds.), Culturally responsive mathematics education (pp. 253-270). Routledge.

Motivate Lab (2018). Build connections: A collaboration to improve a teacher led utility value intervention. Retrieved from https://static1.squarespace.com/static/58290cf0b8a79bc71b31a705/t/5bd71ffd0d929731 6b6bc90c/1540825092595/BC_execsummary_10.29.2018.MMdocx.pdf

National Council of Teachers of Mathematics. (1989). Curriculum and evaluation standards for school mathematics. Author.

National Council of Teachers of Mathematics. (2000). Principles and standards for school mathematics. Author. 
National Governors Association Center for Best Practices \& Council of Chief State School Officers. (2010). Common core state standards. Washington, DC.

National Science Foundation. (2012). Science and engineering indicators 2012. Author.

Retrieved from http://www.nsf.gov/statistics/seind12/

Nolan, K. (2009). Mathematics in and through Social Justice: Another Misunderstood Marriage? Journal of Mathematics Teacher Education, 12, 205-216.

Oakes, J. (2005). Keeping track. Yale University Press.

Paunesku, D., Walton, G. M., Romero, C., Smith, E. N., Yeager, D. S., \& Dweck, C. S. (2015). Mind-set interventions are a scalable treatment for academic underachievement. Psychological science, 26, 784-793. https://doi.org/10.1177/0956797615571017

Powell, A. B., \& Brantlinger, A. (2008). A pluralistic view of critical mathematics. In Proceedings of the fifth international mathematics education and society conference (pp. 424-433). Lisbon, PT: Centro de Investigaçao em Educação, Universidade de Lisboa-Department of Education, Learning, and Philosophy, Aalborg University.

Prediger, D. J. (1982). Dimensions underlying Holland's hexagon: Missing link between interests and occupations? Journal of Vocational Behavior, 21, 259-287. https://doi.org/10.1016/0001-8791(82)90036-7

Priniski, S. J., Hecht, C. A., \& Harackiewicz, J. M. (2018). Making learning personally meaningful: A new framework for relevance research. The Journal of Experimental Education, 86, 11-29. https://doi.org/10.1080/00220973.2017.1380589

Rosenzweig, E. Q., Hulleman, C. S., Barron, K. E., Kosovich, J. J., Priniski, S. J., \& Wigfield, A. (2019). Promises and pitfalls of adapting utility value interventions for online math courses. The Journal of Experimental Education, 87, 332-352.

https://doi.org/10.1080/00220973.2018.1496059 
Rosenzweig, E. Q., \& Wigfield, A. (2016). STEM motivation interventions for adolescents: A promising start, but further to go. Educational Psychologist, 51, 146-163. https://doi.org/10.1080/00461520.2016.1154792

Shechter, O. G., Durik, A. M., Miyamoto, Y., \& Harackiewicz, J. M. (2011). The role of utility value in achievement behavior: The importance of culture. Personality and Social Psychology Bulletin, 37, 303-317. https://doi.org/10.1177/0146167210396380

Shin, D. D., Lee, M., Ha, J. E., Park, J. H., Ahn, H. S., Son, E., Chung, Y., \& Bong, M. (2019). Science for all: Boosting the science motivation of elementary school students with utility value intervention. Learning and Instruction, 60, 104-116. https://doi.org/10.1016/j.learninstruc.2018.12.003

Simic-Muller, K. (2015). Social justice and proportional reasoning. Mathematics Teaching in the Middle School, 21, 162-168. https://doi.org/10.5951/mathteacmiddscho.21.3.0162

Simic-Muller, K., Fernandes, A., \& Felton-Koestler, M. D. (2015). “I just wouldn't want to get as deep into it": Preservice teachers' beliefs about the role of controversial topics in mathematics education. Journal of Urban Mathematics Education, 8(2), 53-86.

Sims, J. J. (2016). Man up: Implementing critical pedagogy for social justice in a STEM-focused 6th-8th grade after school program for African American males. [Doctoral dissertation, University of California, Berkeley]. ProQuest Dissertations Publishing. http://search.proquest.com/pqdtglobal/docview/1815781779/abstract/F9365B89D56A4B $\mathrm{D} 7 \mathrm{PQ} / 1$

Skovsmose, O. (1994). Towards a critical mathematics education. Educational Studies in Mathematics, 27, 35-57.

Stage, F. K., \& Wells, R. S. (2014). Critical Quantitative Inquiry in Context. New Directions for Institutional Research, 2013(158), 1-7. https://doi.org/10.1002/ir.20041 
Stinson, D. W. (2004). Mathematics as "Gate-Keeper" (?): Three theoretical perspectives that aim toward empowering all children with a key to the gate. The Mathematics Educator, $14,8-18$.

Tate, W. F. (1995). Returning to the root: A culturally relevant approach to mathematics pedagogy. Theory Into Practice, 34, 166-173.

https://doi.org/10.1080/00405849509543676

Teranishi, R. T. (2007). Race, ethnicity, and higher education policy: The use of critical quantitative research. New Directions for Institutional Research, 133, 37-49. https://doi.org/10.1002/ir.203

Tibbetts, Y., Harackiewicz, J. M., Canning, E. A., Boston, J. S., Priniski, S. J., \& Hyde, J. S. (2016). Affirming independence: Exploring mechanisms underlying a values affirmation intervention for first-generation students. Journal of Personality and Social Psychology, 110, 635 -659. https://doi.org/10.1037/pspa0000049

Tibbetts, Y., Priniski, S. J., Hecht, C. A., Borman, G. D., \& Harackiewicz, J. M. (2018). Different institutions and different values: Exploring first-generation student fit at 2-year colleges. Frontiers in Psychology, 9:502. https://doi.org/10.3389/fpsyg.2018.00502

Torres, L. (2009). Latino definitions of success: A cultural model of intercultural competence. Hispanic Journal of Behavioral Sciences, 31, 576-593. https://doi.org/10.1177/0739986309349186

Trexler, L. (2013). Adventures of a beginning teacher with social justice mathematics. In E. Gutstein \& Peterson, B. (Eds.), Rethinking mathematics: Teaching social justice by the numbers (2nd ed., pp. 54-60). Rethinking Schools, Ltd.

Turner, E. E. (2003). Critical mathematical agency: Urban middle school students engage in mathematics to investigate, critique, and act upon their world. [Doctoral dissertation, University of Texas at Austin]. ProQuest Dissertations Publishing. 
Turner, E. E. \& Strawhun, B. T. F. (2013). "With math, it's like you have more defense." In E. Gutstein \& Peterson, B. (Eds.), Rethinking mathematics: Teaching social justice by the numbers (2nd ed., pp. 129-137). Rethinking Schools, Ltd.

U.S. Department of Education. (1997). Mathematics equals opportunity. White Paper prepared for U.S. Secretary of Education Richard W. Riley. Retrieved from http://www.ed.gov/pubs/math/mathemat.pdf

Villarejo, M., Barlow, A. E., Kogan, D., Veazey, B. D., \& Sweeney, J. K. (2008). Encouraging minority undergraduates to choose science careers: career path survey results. CBE- Life Sciences Education, 7, 394-409.

Villarruel, F.A., Carlo, G., Grau, J.M., Azmitia, M., Cabrera, N.J., Chahin, T.J. (Eds.). (2009). Handbook of U.S. Latino psychology: Developmental and community-based perspectives. Sage.

Wager, A., \& Stinson, D. W. (Eds.). (2012). Teaching mathematics for social justice: Conversations with mathematics educators. National Council of Teachers of Mathematics.

Walton, G. M. (2014). The new science of wise psychological interventions. Current Directions in Psychological Science, 23, 73-82. https://doi.org/10.1177/0963721413512856

Wang, M. T., \& Eccles, J. S. (2013). School context, achievement motivation, and academic engagement: A longitudinal study of school engagement using a multidimensional perspective. Learning and Instruction, 28, 12-23. https://doi.org/10.1016/j.learninstruc.2013.04.002

Wigfield, A. (1994). Expectancy-value theory of achievement motivation: A developmental perspective. Educational Psychology Review, 6, 49-78.

Wigfield, A, Eccles, J. S., Fredricks, J., Simpkins, Roeser R., \& Schiefele, U. (2015). Development of achievement motivation and engagement. In R. Lerner (Series ed.), M. 
Lamb, \& C. Garcia Coll (Vol. Eds.), Handbook of child psychology and developmental science (7th ed., Vol. 3, pp. 657-700). Wiley.

Wilson, T. D. (2006). The power of social psychological interventions. Science 313, 1251-52. https://doi.org/10.1126/science.1133017

Woolley, M. E., Rose, R. A., Orthner, D. K., Akos, P. T., \& Jones-Sanpei, H. (2013). Advancing academic achievement through career relevance in the middle grades: A longitudinal evaluation of CareerStart. American Educational Research Journal, 50, 1309-1335. https://doi.org/10.3102/0002831213488818

Yeager, D. S., Bundlick, M. J., \& Johnson, R. (2012). The role of future work goals motives in adolescent identity development: A longitudinal mixed-methods investigation. Contemporary Educational Psychology, 27, 206-217. https:// doi.org/10.1016/j.cedpsych.2012.01.004

Yeager, D. S., Henderson, M. D., Paunesku, D., Walton, G. M., D’Mello, S., Spitzer, B. J., \& Duckworth, A. L. (2014). Boring but important: A self-transcendent purpose for learning fosters academic self-regulation. Journal of Personality and Social Psychology, 107, 559-580. https://doi.org/10.1037/a0037637

Yeager, D. S., \& Walton, G. M. (2011). Social-psychological interventions in education: They're not magic. Review of Educational Research, 81, 267-301. https://doi.org/10.3102/0034654311405999 